\title{
Exclusive contracts in bilaterally duopolistic industries
}

\author{
Barna Bakóa,1 \\ ${ }^{a}$ Department of Microeconomics, Corvinus University of Budapest, \\ 1093-H, Budapest, Fövám tér 8, E225.a, Hungary \\ Tel./fax: +3614825140
}

\begin{abstract}
The purpose of this article is to analyze the incentives of manufacturers to deal exclusively with retailers in bilaterally duopolistic industries with brand differentiation by manufacturers. With highly differentiated products exclusive contracts are shown to generate higher profits for manufacturers and retailers, who thus have an incentive to insist on exclusive contracting. However, if the products are close substitutes no exclusivity will emerge in equilibrium.
\end{abstract}

Keywords: exclusive contracts, product differentiation, vertical integration, welfare analysis

JEL Clsaafication Codes: L20, L42, K20, D43, D83

\section{Introduction}

A puzzling feature of many industries is that manufacturers commit themself to sell exclusively through few retailers to the final consumers. At first glance it can be hard to understand why producers would engage to lessen the downstream competition. Intuitively, one would expect that tougher competition leads to lower prices, which implies higher sales for the manufacturer. Yet, we encounter with such exclusive contracts in several industries, with most notable examples in telecommunications ${ }^{1}$ and in the pharmaceutical industry. The practice of exclusive contracts has been a subject of interest

\footnotetext{
Email address: barna.bako@uni-corvinus.hu (Barna Bakó)

${ }^{1}$ For example Apple's and Google's contracts with the mobile service providers regarding selling iPhones and Nexus.

Preprint submitted to Elsevier

November 1, 2010
} 
in the recent literature, though most of the articles study such contracting situations suggesting triangle structures (monopolistic player on one side and duopolistic agents on the other side). While these results have generated important insights about the nature of such contracting games, it is fair to say that the analysis of exclusive contracts in bilaterally oligopolistic markets has been largely ignored in the literature and less is known about the consequences in set-ups where both the upstream and the downstream market contain more then one player. The analysis below focuses on the strategic decision as whether exclusive contracts are profitable in a bilaterally duopolistic setting or not.

It is well known $2^{2}$ that when retailers can observe the contracts offered by a manufacturer to different retailers the joint profit maximizing outcome can be achieved. This result, however, relies crucially on contract observability. If the manufacturer can deal secretly with the retailers a free-riding effect evolves that restrain the parties to achieve the joint profit of an integrated vertical structure. As first shown by Hart and Tirole (1990) in the presence of contract externalities exclusive contracts can be used to solve this problem (see also O'Brien and Shaffer (1992), McAfee and Schwartz (1994) and Segal and Whinston (2003) $)^{3}$ They arrive to the conclusion that a single upstream producer, which sells its product through undifferentiated retailers always offers an exclusive contract to a retailer. Intuitively, in their case there is no loss from selling through a single retailer and contracting externalities are eliminated with exclusive representation. However, this result can be spurious if there is more than one producer. The reason is that while an exclusive contract solves the problem of opportunism between retailers, it pares down the manufacturer's sales, which, if it is unilateral, can lead to less profit for the producer. Such profit reducing effects can outweigh the profit increasing effect arising by solving the problem of contracting externality. Therefore, the producers can experience a prisoners' dilemma in their contracting decision. As we will show in this paper this dilemma will emerge when products produced by manufacturers are sufficiently close substitutes. In this case the producers will abstain from using exclusive contracts.

The paper is organized as follows. Section 2 presents the basic model and analyzes the equilibrium outcomes. Section 3 discusses the welfare implications, and Section 4

\footnotetext{
${ }^{2}$ See Whinston (2006) for discussions of these issues.

${ }^{3}$ The main concern of Hart and Tirole (1990) was vertical integration which was adopted to study exclusive contracts by O'Brien and Shaffer (1992). 
concludes.

\section{The model}

We consider the following vertical structure. There are two upstream manufacturers $\left(M_{1}\right.$ and $\left.M_{2}\right)$ and two downstream retailers $\left(R_{A}\right.$ and $\left.R_{B}\right)$. The manufacturers face constant marginal costs $c_{i},(i=1,2)$, the retailers, in addition to the costs of obtaining the products from the manufacturers have a constant unit cost $c_{j}(j=A, B)$, which are normalized to zero $\left(c_{A}=c_{B}=0\right)$. We assume that final goods are symmetrically differentiated, and the inverse demands for the final good $i$ can be given by

$$
p_{i}\left(q_{i}, q_{-i}\right)=1-q_{i}-\delta q_{-i}
$$

where $i,-i=1,2$, and $\delta \in(0,1)$. We interpret $\delta$ as the degree of product differentiation. For $\delta$ close to 1 downstream firms supply homogenous products, while for $\delta$ close to 0 the firms supply to independent markets.

The game $\Gamma$ we consider is as follows. First, manufacturers decide simultaneously whether or not to offer exclusive contracts to one of the retailers. This decision is observable for every player. Next, if a manufacturer decides not to engage in exclusive contracts, it will make secret offers to each retailer in the form of $\left(q_{i j}, t_{i j}\right)$, with $q_{i j}$ the quantity that the manufacturer $i$ offers to the retailer $j$, and $t_{i j}$ the total transfer that the manufacturer $i$ gets from retailer $j$. In the third step, retailers announce simultaneously whether they accept any of the offers. A retailer that rejects the offers has nothing to sell and earns zero profit. In the final stage quantity competition occurs among retailers, and markets clear.

Due to private contracts, when a retailer receives an offer it has to form a conjecture about the contracts received by the other retailer. Here, we restrict our attention to passive beliefs in which, a retailer after receiving an out of equilibrium offer, continues to believe that the other retailer receives its equilibrium offers (see Segal and Whinston (2003)). Furthermore, if a retailer receives an exclusive contract, then it knows the other retailer has not received any offer from the same manufacturer.

Let $\left(q_{1 A}^{*}, q_{1 B}^{*}, q_{2 A}^{*}, q_{2 B}^{*}, t_{1 A}^{*}, t_{1 B}^{*}, t_{2 A}^{*}, t_{2 B}^{*}\right)$ denote the equilibrium outcome. With passive beliefs if retailer $j(=A)$ receives an offer from manufacturer $i(=1)$ such that 
$\left(q_{1 A}, t_{1 A}\right) \neq\left(q_{1 A}^{*}, t_{1 A}^{*}\right)$ it still believes that the other retailer receives its equilibrium offers $\left(q_{i j}^{*}, t_{i j}^{*}\right)_{i j \neq 1 A}$ and accepts this contract if and only if $p_{1}\left(q_{1 A}+q_{1 B}^{*}, q_{2 A}^{*}+q_{2 B}^{*}\right) q_{1 A} \geq t_{1 A}$ and $p_{2}\left(q_{2 A}^{*}+q_{2 B}^{*}, q_{1 A}+q_{1 B}^{*}\right) q_{2 A}^{*} \geq t_{2 A}^{*}$ respectively. Given this, the manufacturer's offer must be pairwise stable in the sense that

$$
q_{1 A}^{*}=\arg \max _{q_{1 A}}\left[\left(p_{1 A}-c_{1}\right) q_{1 A}+t_{1 B}^{*}-c_{1} q_{1 B}^{*}\right]
$$

which is the joint profit of $M_{1}$ and $R_{A}$. Moreover, these are the same conditions that would hold if the manufacturers wouldn't exist and the retailers would compete as multiproduct duopolists, each with $c_{1}$ and $c_{2}$ product specific marginal costs.

We solve the game by backward induction. First consider the subgame where the manufacturers don't commit themselves to sell exclusively for any of the downstream players and offer a non-exclusive contract to both of the retailers. In equilibrium $\left(q_{1 A}^{*}, q_{1 B}^{*}, q_{2 A}^{*}, q_{2 B}^{*}\right)$ must satisfy

$$
\begin{aligned}
& q_{1 A}^{*}=\arg \max _{q_{1 A}}\left[p_{1}\left(q_{1 A}+q_{1 B}^{*}, q_{2 A}^{*}+q_{2 B}^{*}\right)-c_{1}\right] q_{1 A} \\
& q_{1 B}^{*}=\arg \max _{q_{1 B}}\left[p_{1}\left(q_{1 A}^{*}+q_{1 B}, q_{2 A}^{*}+q_{2 B}^{*}\right)-c_{1}\right] q_{1 B} \\
& q_{2 A}^{*}=\arg \max _{q_{2 A}}\left[p_{2}\left(q_{2 A}+q_{2 B}^{*}, q_{1 A}^{*}+q_{1 B}^{*}\right)-c_{2}\right] q_{2 A} \\
& q_{2 B}^{*}=\arg \max _{q_{2 B}}\left[p_{2}\left(q_{2 A}^{*}+q_{2 B}, q_{1 A}^{*}+q_{1 B}^{*}\right)-c_{2}\right] q_{2 B}
\end{aligned}
$$

which yields

$$
q_{i j}^{*}=\frac{3\left(1-c_{i}\right)-2 \delta\left(1-c_{-i}\right)}{9-4 \delta^{2}}
$$

where $i,-i=1,2 ; i \neq-i$ and $j=A, B$. Equilibrium profits and prices thus equal

$$
\begin{gathered}
\pi_{i}^{*}=\frac{2\left[3\left(1-c_{i}\right)-2 \delta\left(1-c_{-i}\right)\right]^{2}}{\left(9-4 \delta^{2}\right)^{2}} \\
p_{i}^{*}=\frac{3\left(1+2 c_{i}\right)-2 \delta\left(1-c_{-i}\right)-4 \delta^{2} c_{i}}{\left(9-4 \delta^{2}\right)}
\end{gathered}
$$

where $i,-i=1,2$ and $i \neq-i$.

Now consider the case when $M_{1}$ offers an exclusive contract to a retailer, say $R_{A}$. In this case the product of $M_{1}$ is available for purchasing only at $R_{A}$, yet the other manufacturer's product is still available for sale at any retailer. In this case the problem (3) 
boils down to

$$
\begin{aligned}
& q_{1 A}^{*}=\arg \max _{q_{1 A}}\left[p_{1}\left(q_{1 A}+0, q_{2 A}^{*}+q_{2 B}^{*}\right)-c_{1}\right] q_{1 A} \\
& q_{2 A}^{*}=\arg \max _{q_{2 A}}\left[p_{2}\left(q_{2 A}+q_{2 B}^{*}, q_{1 A}^{*}+0\right)-c_{2}\right] q_{2 A} \\
& q_{2 B}^{*}=\arg \max _{q_{2 B}}\left[p_{2}\left(q_{2 A}^{*}+q_{2 B}, q_{1 A}^{*}+0\right)-c_{2}\right] q_{2 B}
\end{aligned}
$$

Solving for $q_{1 A}, q_{2 A}$ and $q_{2 B}$ yields

$$
\begin{gathered}
\pi_{1}^{*}=\frac{\left[3\left(1-c_{1}\right)-2 \delta\left(1-c_{2}\right)\right]^{2}}{4\left(3-\delta^{2}\right)^{2}} \\
\pi_{2}^{*}=\frac{\left[2\left(1-c_{2}\right)-\delta\left(1-c_{1}\right)\right]^{2}}{2\left(3-\delta^{2}\right)^{2}}
\end{gathered}
$$

and

$$
\begin{aligned}
& p_{1}^{*}=\frac{3\left(1+c_{1}\right)-2 \delta\left(1-c_{2}\right)+2 \delta^{2}\left(c_{1}\right)}{2\left(3-\delta^{2}\right)} \\
& p_{2}^{*}=\frac{2\left(1+2 c_{2}\right)-\delta\left(1-c_{1}\right)-2 \delta^{2}\left(c_{2}\right)}{2\left(3-\delta^{2}\right)}
\end{aligned}
$$

Then, by solving the game backward, we obtain the manufacturers' payoffs in the different sub-games at stage 1 as shown in Table 1 .

Table 1: The payoff matrix

\begin{tabular}{ccccc}
\multicolumn{5}{c}{ Table 1: The payoff matrix } \\
\hline \hline & & \multicolumn{3}{c}{$M_{2}$} \\
& & no contract & $R_{A}$ & $R_{B}$ \\
\hline \multirow{4}{*}{$M_{1}$} & no contract & $\left(a_{1}, a_{2}\right)$ & $\left(e_{1}, b_{2}\right)$ & $\left(e_{1}, b_{2}\right)$ \\
& $R_{A}$ & $\left(b_{1}, e_{2}\right)$ & $\left(d_{1}, d_{2}\right)$ & $\left(d_{1}, d_{2}\right)$ \\
& $R_{B}$ & $\left(b_{1}, e_{2}\right)$ & $\left(d_{1}, d_{2}\right)$ & $\left(d_{1}, d_{2}\right)$ \\
\hline
\end{tabular}

where $i,-i=1,2$ and

$\begin{array}{rlrl}a_{i}=\frac{2\left[3\left(1-c_{i}\right)-2 \delta\left(1-c_{-i}\right)\right]^{2}}{\left(9-4 \delta^{2}\right)^{2}} & b_{i} & =\frac{\left[3\left(1-c_{i}\right)-2 \delta\left(1-c_{-i}\right)\right]^{2}}{4\left(3-\delta^{2}\right)^{2}} \\ e_{i}=\frac{\left[2\left(1-c_{i}\right)-\delta\left(1-c_{-i}\right)\right]^{2}}{2\left(3-\delta^{2}\right)^{2}} & d_{i}=\frac{\left[2\left(1-c_{i}\right)-\delta\left(1-c_{-i}\right)\right]^{2}}{\left(4-\delta^{2}\right)^{2}}\end{array}$

The game has several equilibria depending on the level of product differentiation. One can easily see that if $\delta \in(\sqrt{2-\sqrt{2}}, 1)$ the unique subgame perfect equilibria is when the manufacturers don't engage in exclusive contracting and both of them offer a contract to 
the retailers with strictly positive quantities such that condition $(3)$ is satisfied. On the other hand, if the products are highly differentiated, i.e. $\delta \in\left(0, \frac{\sqrt{3(2-\sqrt{2})}}{2}\right)$, both manufacturers will offer an exclusive contract to a retailer. Under intermediate differentiation levels, that is when $\delta \in\left(\frac{\sqrt{3(2-\sqrt{2})}}{2}, \sqrt{2-\sqrt{2}}\right)$, both outcomes can emerge in equilibrium. Note that there is no equilibrium in which only one of the manufacturer would offer an exclusive contract to a retailer. This can occur only under mixed strategies.

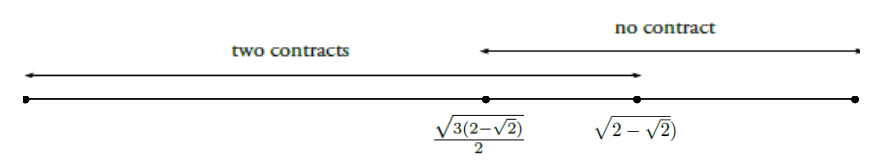

Figure 1: Equilibrium outcomes as a function of product differenctiation.

The following proposition characterizes the equilibrium of the contracting game.

Proposition 2.1. Under highly differentiated products manufacturers engage in exclusive contracting, while when the products are less differentiated the manufacturers will offer non-exclusive contracts to the retailers.

The intuition for the results captured in Proposition 2.1 is straightforward. For $\delta$ belonging to the interval $\left(0, \frac{\sqrt{3(2-\sqrt{2})}}{2}\right)$ the product differentiation is too strong and producers use exclusive contracts to solve the problem of contracting externality. If both manufacturers happen to sign an exclusive contract with the same retailer, the other retailer is driven out from the market, however this is not an explicit purpose for manufacturers. On the other hand, if the products are close substitutes producers are experiencing a prisoners' dilemma. Exclusive contracts still could solve the problem caused by contract externalities, but by using unilateral exclusive contract a manufacturer restricts its output, which primarily benefits the other firm. The firm without exclusivity gains from the restriction of output by the other firm, without having to restrict output himself. The manufacturer with an exclusive contracts commits himself to be less aggressive, which ultimately has a negative effect on his profit. Therefore, in equilibrium both manufacturers will choose to sell without exclusive contracts. 


\section{Welfare implications}

This section discusses the welfare implications of our model. To evaluate consumer welfare we consider a representative consumer's utility function which is consistent with the demand system given by (1). Such a utility in monetary units of consuming $q_{i}$ units of product $i$, and $q_{j}$ units of product $j$, can be given as

$$
U\left(q_{i}, q_{-i}\right)=q_{i}+q_{-i}-\frac{1}{2}\left(q_{i}^{2}+2 \delta q_{i} q_{-i}+q_{-i}^{2}\right)
$$

Plugging into this the equilibrium quantities and substracting the costs involved by consuming these quantities, we get the consumer surpluses for the different sub-cases. Denote by $C W^{n c}$ the consumer welfare that would prevail in the case when manufacturers don't sign exclusive contracts, and by $C W^{1 k 2 l}(k, l=A, B)$ when both manufacturers sign an exclusive contracts. It can be shown that

\section{Proposition 3.1.}

$$
C W^{n c}>C W^{1 k 2 l} \quad k, l=A, B
$$

always holds.

Thus, a social planner who is more concerned about the consumer welfare than the total surplus, should ban the practice of exclusive contracts. To evaluate the welfare effects, we compare the situations with exclusive contracts to the situation in which exclusivity is not possible. Social welfare is given by

$$
W=C W+\pi_{1}+\pi_{2}
$$

where $\pi_{i}$ represents the joint profits of manufacturer $i$ and his downstream retailer(s). Using the consumers' welfare and equilibrium profit levels given in Section 1, yields the following $(k, l=A, B)$

$$
W^{n c}>W^{1 k 2 l} \quad \text { for } \quad \delta \in(0, \sqrt{2-\sqrt{2}})
$$

We already know that in the case when manufacturers produce highly differentiated products they would engage in exclusive dealing in their practice of selling their products. The outcome emerging in equilibrium always leads to a smaller aggregate surplus, compared to the case where using exclusive contracts is not possible. Moreover, if the products are close substitutes the profits gain by manufacturers exceeds the loss of consumer welfare 
caused by exclusive contracts. However in this case the outcome with exclusives will not emerge in the equilibrium. This is summarized in the following proposition.

Proposition 3.2. Social welfare in the case in which manufacturers sell with nonexclusive contracts exceeds social welfare in the case in which manufacturers sell their products exclusively if the products produced by the manufacturers are highly differentiated.

\section{Conclusion}

In the prevailing literature on exclusive contracts it has been argued that manufacturers will engage in using exclusive contracts when products are undifferentiated, and will never sign such contracts, if the products are highly differentiated. This result, however, depends crucially on the fact that the upstream market is supposed to be monopolistic. The results change if we consider multiplayer upstream market. As we have shown in this paper, the manufacturers will engage in exclusive contracting when the product differentiation is strong. In this case an exclusivity will solve the problem of contract externality. If the products are less differentiated the manufacturers experience a prisoner's dilemma, where, by having an incentive to solve the externality problem, a unilateral switch leads to a lower profit. In this case manufacturers will offer non-exclusivity to the retailers. The outcome with no exclusive dealing is shown to generate higher consumer welfare, as well as higher aggregate surplus.

d'Aspremont, C., Gabszewicz, J. and Thisse, J (1979), "On Hotelling's Stability in Competition", Econometrica, 1145-1151.

O'Brien, D. P. and Shaffer, G. (1992). "Vertical Control with Bilateral Contracts", RAND Journal of Economies, 299-308.

Hart, O. and Tirole, J. (1990), "Vertical Integration And Market Foreclosure", Brookings Papers on Economic Activity, 205-276.

McAfee, R. P. and Schwartz, M. (1994), "Opportunism in vertical contracting: Nondiscrimination, exclusivity, and uniformity", American Economic Review, 210-230.

Salant, S., Switzer, S. and Reynolds, R. (1983), "Losses from Horizontal Merger: The Effects of an Exogenous Change in Industry Structure on Cournot-Nash Equilibrium", Quarterly Journal of Economics, 185-199.

Segal, I. and Whinston, M. D. (2003), "Robust predictions for bilateral contracting with externalities", Econometrica, 757-791.

Whinston, M. D. (2006), Lectures on Antitrust Economics, MIT Press, Cambridge, Massachusetts. 